\title{
Reação de genótipos de pessegueiro à podridão parda
}

\section{Brown rot fruit reaction in different peach genotypes}

\author{
Keli Cristina Fabiane \\ Instituto Federal de Santa Catarina - IFSC \\ E-mail: keli.fabiane@ifsc.edu.br \\ OrclD: 0000-0002-5151-6221
}

\begin{abstract}
Kamila Cristina Fabiane
Universidade Tecnológica Federal do Paraná - UTFPR, campus Pato Branco

E-mail: kamilafabiane@yahoo.com.br

OrclD: 0000-0003-4192-1028
\end{abstract}

Jéssica Scarlet Alves de Oliveira Hossel

Universidade Tecnológica Federal do Paraná - UTFPR, campus Pato Branco

E-mail: jeh.alves93@hotmail.com

OrcID: 0000-0002-3274-7155

Cristiano Hossel

Universidade Tecnológica Federal do Paraná - UTFPR, campus Pato Branco

E-mail: cristianohossel@gmail.com

OrclD: 0000-0002-2364-4103

Américo Wagner Júnior

Universidade Tecnológica Federal do Paraná - UTFPR, campus Dois Vizinhos

E-mail: americowagner@utfpr.edu.br

OrclD: 0000-0001-5081-5281

Idemir Citadin

Universidade Tecnológica Federal do Paraná - UTFPR, campus Pato Branco

E-mail: idemir@utfpr.edu.br

OrclD: 0000-0001-9416-2761

Resumo A podridão parda, causada pelo fungo Monilinia fructicola (Wint.) Honey, é a principal doença das fruteiras de caroço. Ataca flores, ramos e frutos das plantas hospedeiras, causando severas perdas. Assim, é importante identificar genótipos com alguma resistência à podridão parda, uma vez que podem ser recomendados para uso em programas de melhoramento como futuros genitores em hibridações controladas. O objetivo deste trabalho foi testar a reação dos frutos em genótipos de pessegueiro à podridão parda. Foram avaliados 26 e 29 genótipos de pessegueiro no ciclo produtivo 2009/2010 e 2010/2011, respectivamente. O experimento foi realizado no Laboratório de Fitossanidade da UTFPR - Câmpus Dois Vizinhos. O delineamento experimental foi inteiramente casualizado, considerando-se cada genótipo de pessegueiro como tratamento, utilizando-se três repetições com nove frutos cada. A inoculação foi realizada sobre a epiderme dos frutos com aspersão de suspensão conidial $\left(1,0 \times 10^{5}\right.$ esporosmL $\left.\mathrm{L}^{-1}\right)$ de aproximadamente $0,15 \mathrm{~mL}$ de $\mathrm{M}$. fructicola. Os frutos foram observados 72 e 120 horas após a inoculação, sendo avaliada a incidência e severidade da doença. Os genótipos de pessegueiro diferiram para todas as variáveis analisadas (incidência e severidade) nos dois ciclos produtivos. Frutos dos genótipos 'TropicBeauty', 'Bonão', 'Cascata 962', 'Conserva 1187', 'Kampai', 'Cascata 1063', 'TropicSnow' e 'Rubimel' foram os que apresentaram menor incidência a podridão parda nos ciclos produtivos 2009/2010 e 2010/2011.

Palavras-chave: melhoramento, Monilinia fructicola, Prunus sp., resistência 


\begin{abstract}
The brown rot caused by the fungus Monilinia fructicola (Wint.) Honey is the main disease of stone fruits. This attacks the flowers, stems and fruit of host plants, causing severe losses. Thus, it is important to identify genotypes with brown rot resistance to be recommended for using as parents in future breeding programs. The aim of this work was to test the different peach genotypes for brown rot reaction in fruits. Twentysix and 29 peach genotypes were evaluated in the 2009/2010 and 2010/2011 production cycle, respectively. The experiment was carried out at the Laboratório de Fitossanidade, da UTFPR - Campus Dois Vizinhos. The experimental design was entirely randomized, considering each peach genotype a treatment, and it was use three replications of nine fruits by plot. The fruit epidermis was inoculated individually with $0.15 \mathrm{~mL}$ of $M$. fructicola conidial suspension $\left(1.0 \times 10^{5}\right.$ spores $\left.\mathrm{mL}^{-1}\right)$. The fruit were examined 72 and 120 hours after inoculation, and the disease incidence and severity were evaluated. Peach genotypes differed significantly for all variables evaluated (incidence and severity) in both production cycles. Fruits from 'Tropic Beauty 'Bonão', 'Cascata 962', 'Conserva 1187', 'Kampai', 'Cascatal 1063', 'Tropic Snow' and 'Rubimel' genotypes showed the lowest brown rot incidence in 2009/2010 and 2010/2011 cycles.
\end{abstract}

Keywords: breeding, Monilinia fructicola, Prunus sp., resistance

Data de recebimento: $31 / 07 / 2018$

Data de aprovação: 31/10/2019

DOI: https://doi.org/10.30612/agrarian. v13i49.8508

\title{
Introdução
}

Os frutos de pessegueiro (Prunus persica) são alvos de doenças e tem sua qualidade e produção reduzida em determinadas condições, principalmente se associado ao ataque de pragas, que servem de porta de entrada para patógenos (Wagner Júnior et al., 2008). A podridão parda é considerada uma das doenças mais importantes do mundo (Papavasileiou et al., 2015), responsável por perdas nas fases de pré e pós-colheita da cultura (Guinet et al., 2016).

Quando infectados, pelo fungo Monilinia fructicola (Wint.) Honey, observam-se nos frutos manchas pequenas, com formas circulares, de coloração parda (May-de Mio et al., 2008). O desenvolvimento da doença é rápido, causando a desidratação e mumificação dos frutos, que podem permanecer aderidos à planta ou caírem ao solo, mantendo o fungo.

A podridão parda é favorecida pelas condições de clima temperado, realidade encontrada nas principais regiões produtoras do Rio Grande do Sul e Santa Catarina (Negri et al., 2011). Em virtude desta condição, são necessárias várias aplicações preventivas de fungicidas para controlar a doença sendo, até o momento, de melhor eficiência (Pavanello et al., 2015), mas de maior impacto ao ambiente e consumidores.

Em busca de alimentação saudável, o ser humano tem se preocupado mais com o uso excessivo de produtos químicos nos frutos, principalmente em aplicações na pós-colheita (Barreto et al., 2016). Além disso, a legislação sanitária atua de forma mais rigorosa na última década, pela busca de produtos sem resíduos nos frutos (Basseto et al., 2007). Assim, é necessário buscar alternativas para não utilização de fungicidas, ou quando realizada de forma minimizada. O fator genético do pessegueiro pode ser opção (Wagner Júnior et al., 2011) de estudo, pois é verificada diferentes respostas pelos genótipos de pessegueiro a podridão parda (Santos et al., 2012). Ressalta-se, porém, que ainda não existem genótipos com elevado grau de resistência a doença (Danner et al., 2008).

A identificação de genótipos com resistência à podridão parda, é importante, uma vez que estes podem ser recomendados em programas de melhoramento como futuros genitores em hibridações controladas. Assim, o objetivo deste trabalho foi testar a reação de resistência ou suscetibilidade causada nos frutos de genótipos de pessegueiro submetidos à podridão parda.

\section{Materiais e Métodos}


A avaliação dos genótipos de pessegueiro quanto à reação dos frutos a podridão parda foi realizada no Laboratório de Fitossanidade, da UTFPR (Universidade Tecnológica Federal do Paraná) - Câmpus Dois Vizinhos, nos ciclos produtivos 2009/2010 e 2010/2011.

No ciclo produtivo 2009/2010, foram avaliados 26 genótipos de pessegueiro, destes nove cultivares e 17 seleções. No ciclo 2010/2011, a avaliação se deu em 29 genótipos, sendo oito cultivares e 21 seleções.

Os frutos avaliados foram provenientes da coleção de pessegueiro da área experimental da UTFPR -

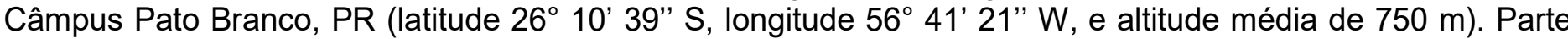
dessa coleção foi implantada em setembro de 2003 e segunda remessa de genótipos de pessegueiro em 2004 .

As plantas de cada genótipo foram conduzidas em sistema de vaso, com espaçamento de $5 \times 4 \mathrm{~m}$ entre planta e linha. As práticas de manejo, foram realizadas conforme as recomendações existentes para a cultura. Na segunda semana de outubro, do ciclo 2010/2011, foi realizada aplicação de fungicida (azoxistrobina).

O delineamento experimental foi inteiramente casualizado, considerando-se cada genótipo de pessegueiro como tratamento, utilizando-se três repetições com nove frutos cada.

Os frutos, já em laboratório, foram novamente selecionados e aqueles que apresentaram injúrias, infecção aparente e/ou danos mecânicos, foram descartados. Os frutos em estádio de maturação fisiológica selecionados foram desinfestados com solução de hipoclorito de sódio a 0,25\%, sendo imersos por 1 minuto e, após 10 minutos, lavados três vezes com água destilada (Wagner Júnior et al., 2008).

O fungo foi obtido a partir de frutos infectados com $M$. fructicola provenientes da coleção de pessegueiros da UTFPR e de pomares comerciais da região, procurando-se obter mais de um isolado do mesmo patógeno. Após a coleta, o material foi levado para laboratório, sendo os esporos contidos nos frutos misturados e transferidos com estilete para placas de Petri®, contendo meio BDA (Batata Dextrose Ágar) e incubadas em câmara B.O.D a $25 \pm 2^{\circ} \mathrm{C}$, por 5-7 dias, em fotoperíodo de escuro total. A contaminação com outros fungos foi eliminada através de sucessivas repicagens até a obtenção de cultura pura.

Para obtenção da suspensão conidial, com auxílio de câmara de Neubauer foram adicionados $10 \mathrm{~mL}$ de água destilada nas placas de Petri®, contendo a cultura. Posteriormente, sucessivas diluições a concentração da suspensão de $M$. fructicola foi ajustada para 1,0 × $10^{5}$ esporos $\mathrm{mL}^{-1}$ (Bassi et al., 1998).

A inoculação de $M$. fructicola foi realizada pela aspersão de solução conidial de aproximadamente 0,15 $\mathrm{mL}$ do fungo, sobre a epiderme dos frutos.

O procedimento foi realizado sobre área com $2,5 \mathrm{~cm}$ de diâmetro na superfície da fruta com borrifador plástico. A inoculação foi realizada em câmara de fluxo laminar. Após a inoculação, os frutos foram acondicionados sobre anéis de policloreto de vinila (PVC), dentro de caixas plásticas $(24,0 \times 23,0 \times 10,0 \mathrm{~cm})$ umedecidas e fechadas (com pequenos orifícios nas laterais) e forradas com papel toalha umedecido. As caixas foram mantidas em ambiente natural. Foram utilizados frutos em estádio de maturação fisiológica, sendo nove por cada caixa. Os frutos foram avaliados 72 e 120 horas após a inoculação e, foi observado a incidência da doença, expresso em \% de frutos contaminados, e individualmente a severidade de infecção do fruto atacado, baseados na escala de 0 a 4 (Tabela 1) (Wagner Júnior et al., 2005).

Tabela 1. Escala da severidade da doença causada pelo fungo M. fructicola em pêssegos (Wagner Júnior et al., 2005).

\begin{tabular}{ll}
\hline Escala & Severidade da doença \\
\hline 0 & Fruto sem infecção \\
1 & $>0 \% \leq 25 \%$ da superfície do fruto com lesão da doença \\
2 & $>25 \% \leq 50 \%$ da superfí́ie do fruto com lesão da doença \\
3 & $>50 \% \leq 75 \%$ da superfície do fruto com lesão da doença \\
4 & $>75 \%$ da superfície do fruto com lesão da doença \\
\hline
\end{tabular}

Os dados da percentagem de incidência de patógenos e severidade nos frutos foram submetidos à análise de variância e ao teste de Scott \& Knott $(\alpha=0,05)$. Os dados das percentagens de incidência e severidade foram transformados previamente em arco seno $\sqrt{x / 100}$, por não terem apresentado normalidade segundo o teste de Lilliefors.

As análises estatísticas foram realizadas no Aplicativo Computacional em Genética e Estatística, $\operatorname{GENES}^{\circledR}($ Cruz, 2013). 


\section{Resultados e Discussão}

Os genótipos de pessegueiro diferiram para todas as variáveis analisadas nos dois ciclos produtivos. De acordo com as Tabelas 2 e 3, verificou-se que as médias dos genótipos para incidência e severidade da podridão parda nos frutos às 72 e 120 horas posteriores à inoculação, permitiu-se a formação de quatro grupos distintos, no ciclo produtivo 2009/2010 e 2010/2011.

$\mathrm{Na}$ avaliação realizada às 72 horas após a inoculação, durante o ciclo 2009/2010 foram agrupados 18 genótipos como tolerantes ( $<22,22 \%>5 \%$ de incidência) e/ou resistentes ( $<5 \%$ incidência) a podridão parda nos frutos.

No entanto, destes 18 genótipos, somente nove (Cascata 962, Kampai, Conserva 1187, Conserva 1063, Tropic Snow, Rubimel, Cascata 967, Conserva 985 e Conserva 844) mantiveram o comportamento de tolerância a doença ao analisá-los nas 120 horas (Tabela 2).

Isso indica que frutos dos demais nove genótipos podem ter tolerância ao fungo $M$. fructicola nas primeiras 72 horas de contato com o mesmo, porém uma vez instalada a doença o desenvolvimento desta é rápido, como ocorrido para Tropic Beauty (8,34\% para 58,33\%), Bonão (11,11\% para 51,85\%), Conserva 1396 $(11,11 \%$ para $77,78 \%)$, Cascata $1303(7,41 \%$ para 81,48\%), Conserva $1129(0 \%$ para 59,26\%), Cascata 1055 $(22,22 \%$ para $48,15 \%)$, Conserva $1434(14,82 \%$ para $62,96 \%)$, Conserva $1186(7,41 \%$ para $59,26 \%)$, Conserva $871(22,22 \%$ para $88,89 \%)$ nas 120 horas de avaliação (Tabela 2$)$.

Tabela 2. Incidência de podridão parda em frutos de 30 genótipos de pessegueiro, a 72 e 120 horas após inoculados com M. fructicola, nos ciclos produtivos 2009/2010 e 2010/2011

\begin{tabular}{|c|c|c|c|c|}
\hline \multirow[b]{2}{*}{ Genótipos } & \multicolumn{2}{|c|}{ Incidência de podridão $72 \mathrm{~h}$} & \multicolumn{2}{|c|}{ Incidência de podridão $120 \mathrm{~h}$} \\
\hline & $2009 / 2010$ & $2010 / 2011$ & $2009 / 2010$ & $2010 / 2011$ \\
\hline Libra & $41,67 \mathrm{c}$ & $7,41 \mathrm{~d}$ & $87,50 \mathrm{~b}$ & $18,53 \mathrm{~d}$ \\
\hline Tropic Beauty & $8,34 \mathrm{~d}$ & $0,00 \mathrm{~d}$ & $58,33 \mathrm{c}$ & $7,41 \mathrm{~d}$ \\
\hline Bonão & $11,11 d$ & $3,71 \mathrm{~d}$ & $51,85 \mathrm{c}$ & $37,04 \mathrm{c}$ \\
\hline Cascata 962 & $0,00 \mathrm{~d}$ & $0,00 \mathrm{~d}$ & $12,50 \mathrm{~d}$ & $22,23 d$ \\
\hline Conserva 1187 & $20,84 d$ & $3,71 \mathrm{~d}$ & $41,67 d$ & $55,56 \mathrm{c}$ \\
\hline Kampai & $0,00 \mathrm{~d}$ & $0,00 d$ & $25,92 \mathrm{~d}$ & $11,11 d$ \\
\hline Cascata 1063 & $0,00 \mathrm{~d}$ & $0,00 \mathrm{~d}$ & $25,92 \mathrm{~d}$ & $37,03 \mathrm{c}$ \\
\hline Tropic Snow & $11,11 d$ & $11,11 \mathrm{c}$ & $25,92 d$ & $25,93 \mathrm{~d}$ \\
\hline Conserva 1396 & $11,11 \mathrm{~d}$ & $14,82 \mathrm{c}$ & $77,78 \mathrm{~b}$ & 70,37 b \\
\hline Cascata 1303 & $7,41 \mathrm{~d}$ & $0,00 \mathrm{~d}$ & $81,48 b$ & $11,12 d$ \\
\hline Rubimel & $3,71 \mathrm{~d}$ & $0,00 \mathrm{~d}$ & $22,22 \mathrm{~d}$ & $18,52 d$ \\
\hline Conserva 985 & $7,41 \mathrm{~d}$ & $51,83 \mathrm{~b}$ & $18,53 d$ & $70,37 \mathrm{~b}$ \\
\hline Conserva 1153 & $70,37 \mathrm{~b}$ & $100,00 a$ & $100,00 \mathrm{a}$ & 100,00 a \\
\hline Cascata 967 & $0,00 \mathrm{~d}$ & 92,59 a & $18,52 d$ & $96,30 \mathrm{a}$ \\
\hline Conserva 844 & $11,12 \mathrm{~d}$ & $55,56 \mathrm{~b}$ & $33,33 d$ & $88,89 a$ \\
\hline Conserva 1129 & $0,00 \mathrm{~d}$ & $88,89 a$ & $59,26 \mathrm{c}$ & $96,30 \mathrm{a}$ \\
\hline Cascata 1070 & $44,45 \mathrm{c}$ & $44,45 \mathrm{~b}$ & $92,59 a$ & $100,00 \mathrm{a}$ \\
\hline Cascata 1055 & $22,22 \mathrm{~d}$ & $77,78 \mathrm{~b}$ & $48,15 \mathrm{c}$ & 96,30 a \\
\hline Atenas & $100,00 a$ & $92,59 a$ & $100,00 a$ & $100,00 \mathrm{a}$ \\
\hline Conserva 1434 & $14,82 \mathrm{~d}$ & $59,26 \mathrm{~b}$ & $62,96 \mathrm{c}$ & 96,30 a \\
\hline Conserva 1186 & $7,41 \mathrm{~d}$ & $62,96 \mathrm{~b}$ & $59,26 \mathrm{c}$ & $100,00 \mathrm{a}$ \\
\hline Cascata 587 & $48,15 \mathrm{c}$ & 77,78 a & 96,30 a & 96,30 a \\
\hline Conserva 681 & $100,00 a$ & $25,92 \mathrm{c}$ & $100,00 \mathrm{a}$ & $59,26 \mathrm{c}$ \\
\hline Conserva 871 & $22,22 \mathrm{~d}$ & 85,19 a & $88,89 a$ & $96,30 \mathrm{a}$ \\
\hline Âmbar & $77,78 \mathrm{~b}$ & $59,26 \mathrm{~b}$ & $100,00 \mathrm{a}$ & 81,48 b \\
\hline Santa Áurea & $37,04 \mathrm{c}$ & - & 77,78 b & - \\
\hline Conserva 1223 & - & $44,44 \mathrm{~b}$ & - & 66,67 b \\
\hline Conserva 1127 & - & $100,00 \mathrm{a}$ & - & $100,00 \mathrm{a}$ \\
\hline Conserva 1216 & - & $100,00 a$ & - & 100,00 a \\
\hline Cascata 1065 & - & $14,81 \mathrm{c}$ & - & $40,74 \mathrm{c}$ \\
\hline
\end{tabular}

*Médias seguidas pela mesma letra na coluna não diferem entre si, pelo teste Scott \&Knott $(\alpha=0.05) .{ }^{* *} \mathrm{CV}($ Coeficiente de variação). 
Tabela 3. Severidade de podridão parda em frutos de 30 genótipos de pessegueiro, a 72 e 120 horas após inoculação nos ciclos 2009/2010 e 2010/2011

\begin{tabular}{|c|c|c|c|c|}
\hline \multirow{2}{*}{ Genótipos } & \multicolumn{2}{|c|}{ Severidade ${ }^{* \star *}$ de podridão $72 \mathrm{~h}$} & \multicolumn{2}{|c|}{ Severidade de podridão $120 \mathrm{~h}$} \\
\hline & $2009 / 2010$ & $2010 / 2011$ & $2009 / 2010$ & 2010/2011 \\
\hline Libra & $0,74 \mathrm{c}^{*}$ & $0,07 \mathrm{~d}$ & $1,96 \mathrm{~b}$ & $0,22 \mathrm{e}$ \\
\hline Tropic Beauty & $0,13 d$ & $0,0 \mathrm{~d}$ & $1,29 \mathrm{c}$ & $0,07 \mathrm{e}$ \\
\hline Bonão & $0,15 d$ & $0,04 d$ & $1,37 \mathrm{c}$ & $0,44 \mathrm{e}$ \\
\hline Cascata 962 & $0,0 \mathrm{~d}$ & $0,0 d$ & $0,13 c$ & $0,22 \mathrm{e}$ \\
\hline Conserva 1187 & $0,25 d$ & $0,04 \mathrm{~d}$ & $1,04 \mathrm{c}$ & $0,56 \mathrm{e}$ \\
\hline Kampai & $0,0 \mathrm{~d}$ & $0,0 \mathrm{~d}$ & $0,52 \mathrm{c}$ & $0,74 \mathrm{e}$ \\
\hline Cascata 1063 & $0,0 \mathrm{~d}$ & $0,0 \mathrm{~d}$ & $0,33 \mathrm{c}$ & $0,41 \mathrm{e}$ \\
\hline Tropic Snow & $0,15 d$ & $0,11 d$ & $0,37 \mathrm{c}$ & $0,48 \mathrm{e}$ \\
\hline Conserva 1396 & $0,22 d$ & $0,19 \mathrm{~d}$ & $1,96 \mathrm{~b}$ & $1,11 \mathrm{~d}$ \\
\hline Cascata 1303 & $0,08 d$ & $0,0 \mathrm{~d}$ & $2,11 \mathrm{~b}$ & $0,15 \mathrm{e}$ \\
\hline Rubimel & $0,04 \mathrm{~d}$ & $0,0 \mathrm{~d}$ & $0,29 \mathrm{c}$ & $0,22 \mathrm{e}$ \\
\hline Conserva 985 & $0,08 d$ & $0,70 \mathrm{c}$ & $0,30 \mathrm{c}$ & $1,52 \mathrm{~d}$ \\
\hline Conserva 1153 & $1,19 b$ & $2,00 a$ & $2,92 \mathrm{a}$ & $3,52 \mathrm{a}$ \\
\hline Cascata 967 & $0,0 \mathrm{~d}$ & $1,15 \mathrm{c}$ & $0,18 \mathrm{c}$ & $3,07 \mathrm{a}$ \\
\hline Conserva 844 & $0,11 d$ & $0,59 d$ & $0,59 \mathrm{c}$ & $1,89 \mathrm{c}$ \\
\hline Conserva 1129 & $0,0 \mathrm{~d}$ & $1,48 \mathrm{~b}$ & $1,04 \mathrm{c}$ & $3,11 \mathrm{a}$ \\
\hline Cascata 1070 & $0,48 \mathrm{c}$ & $0,70 \mathrm{c}$ & $2,26 \mathrm{~b}$ & $2,44 \mathrm{~b}$ \\
\hline Cascata 1055 & $0,26 \mathrm{~d}$ & $0,89 \mathrm{c}$ & $0,67 \mathrm{c}$ & $2,93 a$ \\
\hline Atenas & $2,00 a$ & $1,44 \mathrm{~b}$ & $3,67 \mathrm{a}$ & $3,56 a$ \\
\hline Conserva 1434 & $0,18 d$ & $0,70 \mathrm{c}$ & $0,85 \mathrm{c}$ & $2,67 \mathrm{~b}$ \\
\hline Conserva 1186 & $0,07 \mathrm{~d}$ & $0,74 \mathrm{c}$ & $0,82 \mathrm{c}$ & $2,52 \mathrm{~b}$ \\
\hline Cascata 587 & $0,56 \mathrm{c}$ & $0,96 \mathrm{c}$ & $2,56 \mathrm{~b}$ & $2,56 \mathrm{~b}$ \\
\hline Conserva 681 & $2,26 a$ & $0,26 \mathrm{~d}$ & $3,63 a$ & $0,82 \mathrm{~d}$ \\
\hline Conserva 871 & $0,22 d$ & $1,11 \mathrm{c}$ & $1,78 b$ & $2,11 \mathrm{c}$ \\
\hline Âmbar & $0,78 \mathrm{c}$ & $0,96 \mathrm{c}$ & $2,44 \mathrm{~b}$ & $1,74 \mathrm{c}$ \\
\hline Santa Áurea & $0,52 \mathrm{c}$ & - & $1,67 \mathrm{~b}$ & - \\
\hline Conserva 1223 & - & $0,48 d$ & - & $1,07 d$ \\
\hline Conserva 1127 & - & $1,33 \mathrm{~b}$ & - & $3,44 a$ \\
\hline Conserva 1216 & - & $1,52 b$ & - & $3,41 \mathrm{a}$ \\
\hline \multirow[t]{2}{*}{ Cascata 1065} & - & $0,18 \mathrm{~d}$ & - & $0,56 \mathrm{e}$ \\
\hline & & $6)^{* *}$ & & 41,30 \\
\hline
\end{tabular}

${ }^{*}$ Médias seguidas pela mesma letra na coluna não diferem entre si, pelo teste Scott \&Knott $(\alpha=0.05) .{ }^{* *} \mathrm{CV}$ (Coeficiente de variação)

*** Severidade segundo escala de 0 a 4 , onde 0 para fruto sem infecção, 1 fruto com lesão $>0 \% \leq 25 \%$ da superfície do mesmo, 2 sendo $>25 \% \leq 50 \%$ da superfície do fruto com lesão da doença), 3 com área $>50 \% \leq 75 \%$ da superfície do fruto com lesão da doença) e 4 considerando-se $>75 \%$ da superfície do fruto com lesão da doença (Wagner Júnior et al., 2005).

Resultados semelhantes ocorreram no ciclo produtivo 2010/2011, para os genótipos Bonão (3,71\% para $37,04 \%)$, Conserva 1187 (3,71\% para 55,56\%) e Cascata 1063 (0\% para 37,03\%), comparando-se o progresso da doença das 72 às 120 horas após inoculação, sendo considerados no primeiro tempo de avaliação como no grupo com menor incidência a podridão parda, não sendo a mesma resposta para as 120 horas.

Isto pode estar relacionado aos apontamentos descritos por Schlagbauer e Holz (1989) no qual relataram que a resistência à podridão parda parece estar limitada à epiderme, não havendo qualquer tipo de resistência na polpa das frutas. A penetração do fungo nos frutos de pessegueiro está ligada a estrutura da cutícula dos mesmos (Santos et al., 2012). Assim, supõe-se que nas primeiras 72 horas alguns frutos conseguem retardar a penetração do patógeno, pois ainda o mesmo não atingiu a polpa, mas com 120 horas já ocorre à infecção, sendo estes rapidamente suscetíveis, servindo como fonte de inóculo para contaminação dos demais.

A mesma condição também foi observada por Santos et al. (2012), analisando-se as seleções Conserva 1798, Conserva 1806, Conserva 1596, Conserva 1218 e Cascata 1493, uma vez que apresentaram menor tamanho de lesões até às 72 horas após a inoculação de $M$. fructicola, atribuindo-se a isso a cutícula, no qual pode estar fortemente associada à resistência à podridão parda, retardando a penetração do fungo na polpa até este período.

Tal comportamento faz com que sejam importante o correto manejo do fruto na pós-colheita, uma vez que se houver qualquer dano mecânico na epiderme as chances de contaminação serão maiores. Além disso, 
deve-se ter maior cuidado na classificação e seleção dos frutos durante sua conservação pós-colheita e/ou na sua comercialização, uma vez que, se houver fruto contaminado em determinado lote, as perdas podem ser significativas. Tal condição normalmente é recomendada, mas ainda pouco adotada.

Entretanto, destaca-se que os genótipos Libra, Tropic Beauty, Cascata 962, Kampai, Tropic Snow, Cascata 1303 e Rubimel foram agrupados como aqueles de menor incidência a doença nos frutos nas 120 horas posteriores a inoculação, dentro do ciclo 2010/2011, sendo que para os seis últimos genótipos citados não foi observada incidência de podridão parda nos frutos nas 72 horas após a inoculação, conforme Tabela 2.

Destes, os genótipos 'Kampai' e 'Rubimel' possuem os mesmos genitores ('Chimarrita' x 'Flordaprince'). Os genótipos 'Libra e 'Cascata 1303' possuem em comum o progenitor 'Aldrighi', embora com diferentes graus de parentesco (Fabiane, 2011).

Por outro lado, genótipos como Libra, Bonão, Cascata 1303, Cascata 967, Conserva 844, Conserva 1129, Cascata 1055, Conserva 1434, Conserva 1186 e Conserva 871 apresentaram resultados divergentes quanto à reação à podridão parda nos dois ciclos produtivos (2009/2010 e 2010/2011), sendo considerado tolerante em um destes e suscetível em outro, enfatizando-se a importância da análise por mais de um ciclo para seleção de resistência (Tabela 2).

É provável que a variação do tipo de inóculo utilizado entre os ciclos pode ter possibilitado a utilização de um isolado mais agressivo a esses genótipos em um destes e outra menos em outro. Contudo, a utilização de inóculo com estirpes diferentes é recomendada quando se visa obter resistência horizontal. A resistência vertical é regida por um gene apenas, porém na resistência horizontal, trabalha-se com um grupo de genes (Wagner Júnior et al., 2008; Miranda et al., 2010). Esse tipo de resistência apresenta a vantagem de controlar um espectro maior de raças em população patogênica (Fehr, 1987) devido a sua característica poligênica.

Quanto à severidade da doença foi observado que ela está relacionada com os resultados de incidência de podridão em frutos de alguns genótipos, tanto para menores médias quanto para as maiores obtidas para estas variáveis (Tabela 3 ).

Porém, ressalta-se que no ciclo produtivo 2009/2010, os genótipos Tropic Beauty, Bonão, Cascata 962 , Conserva 1187, Kampai, Cascata 1063, Tropic Snow, Rubimel, Conserva 985, Cascata 967, Conserva 844, Conserva 1129, Cascata 1055, Conserva 1434, Conserva 1186, Conserva 1396, Cascata 1303 e Conserva 871 foram os que apresentaram menor severidade da doença 72 horas após inoculação, com escala de infecção menor que 1, indicando praticamente não haver infecção nos mesmos. Com exceção dos últimos três genótipos citados, os demais mantiveram os resultados de menor severidade nas 120 horas, porém com escala de infecção menor que 2, com área de contaminação do fruto não superior a 25\% (Tabela 3).

Os mesmos resultados de menor severidade nas 72 e 120 horas também foram verificados no ciclo produtivo 2010/2011 para os genótipos Tropic Beauty, Bonão, Cascata 962, Conserva 1187, Kampai, Cascata 1063, Tropic Snow e Rubimel. Neste mesmo ciclo (2010/2011), os genótipos Conserva 1396, Conserva 844 e Conserva 681 estavam entre aqueles com menor severidade somente nas 72 horas, não se repetindo para as 120 horas (Tabela 3 ).

Os genótipos Conserva 1223 e Cascata 1065 apresentaram resultados promissores, devendo os mesmos ser testados em outro ciclo produtivo, já que foram avaliados apenas em 2010/2011 (Tabela 3).

\section{Conclusões}

Frutos dos genótipos 'Tropic Beauty', 'Cascata 962', 'Conserva 1187’, 'Kampai', 'Cascata 1063', 'Tropic Snow' e 'Rubimel' foram os que apresentaram menor incidência e severidade à podridão parda nos ciclos produtivos 2009/2010 e 2010/2011, indicando-as como tolerantes à doença.

\section{Referências}

BARRETO, C.V.; MORENO, M.B.; SILVA, P.S.; MALGARIM, M.B.; FACHINELLO, J.C. Ácido salicílico na póscolheita para redução de podridão parda emanutenção qualidade de pêssego 'Chiripá'. Revista Iberoamericana de Tecnología Postcosecha, v.17, n.1, p.50-57, 2016.

BASSETTO, E.; AMORIM, L.; BENATO, E. A.; GONÇALVES, F. P.; LOURENÇO, S. A. Efeito da irradiação UV$\mathrm{C}$ no controle da podridão parda (Monilinia fructicola) e da podridão mole (Rhizopus stolonifer) em pós-colheita de pêssegos. Fitopatologia Brasileira, v.32, n.5, p. 393-399, 2007. 
BASSI, D.; RIZZO M.; CANTONI, L. Assaying brown rot [Monilinia laxa Adern. Et Ruhl. (Honey)] susceptibility in peach cultivars and progeny. Acta Horticulturae. v. 465, p. 715-722, 1998.

CRUZ, C.D. GENES - a software package for analysis in experimental statistics and quantitative genetics. Acta Scientiarum Agronomy, v.35, p.271-276, 2013.

DANNER, M.A.; SASSO, S.A.Z.; MEDEIROS, J.G.S.; MARCHESE, J.A.; MAZARO, S.M. Indução de resistência à podridão-parda em pêssegos pelo uso de eliciadores em pós-colheita. Pesquisa Agropecuária Brasileira, v.43, n.7, p. 793-799, 2008.

FABIANE, K.C. Reação de pessegueiros a Monilinia fructicola (Wint.) Honey e sua relação com os componentes bioquímicos. Dissertação (Mestrado em Agronomia). UTFPR. 2011, 139 p.

FEHR, W. R. Principles of cultivar development- Theory and Technique. Macmillan Publishing Company, New York, USA.1987, 536p.

GUINET, C.; FOURRIER-JEANDEL, C.; CERF-WENDLING, I.; IOOS, R. One-step detection of Monilinia fructicola, M. fructigena, and M. laxa on Prunus and Malus by a multiplex real-time PCR assay. Plant Disease, v.100, n.12, p.2465-2474, 2016.

MAY-DE MIO, L.L.; MOREIRA, L.M.; MONTEIRO, L.; JUSTINIANO JUNIOR, P. Infecção de Monilinia fructicola no período de floração e incidência de podridão parda em frutos de pessegueiro em dois sistemas de produção. Tropical Plant Pathology, v.33, n.3, p.227-234, 2008.

MIRANDA, B.E.C.; BOITEUX, L.S.; CRUZ, E.M.; REIS, A. Fontes de resistência em acessos de Solanum (secção Lycopersicon) a Verticillium dahliae raças 1 e 2. Horticultura Brasileira. v. 28, p. 458-465, 2010.

NEGRI, G.; BIASI, L.A.; WORDELL FILHO, J.A.; MAY-DE MIO, L.L. Manejo da queima das flores e da podridãoparda do pessegueiro cultivado em sistema orgânico. Revista Brasileira de Fruticultura, Volume Especial, p.415-423, 2011.

PAPAVASILEIOU, A.; TESTEMPASIS, S.; MICHAILIDES, T.J.; KARAOGLANIDIS, G.S. Frequency of brown rot fungi on blossoms and fruit in stone fruit orchards in Greece. Plant Pathology, v.64, p.416-42 4, 2015.

PAVANELLO, E.P.; BRACKMANN, A.; THEWES, F.R.; BOTH, V.; SANTOS, J.R.A.; SCHORR, M.R.W. Efficiency of fungicides in the control of brown rot in peaches and its relationship with physiological parameters of the fruits. Semina: Ciências Agrárias, v.36, n.1, p. 67-76, 2015.

SANTOS, J.; RASEIRA, M.C.B, ZANANDREA, I. Resistence to brown rot in peach plants. Bragantia, v.71, n.2, p.219-225, 2012.

SCHLAGBAUER, H.E.; HOLZ, G. Occurrence of latent Monilinia laxa infections on plums, peaches e apricots. Phytophylactica, v.21 n.1 p.35-38, 1989.

WAGNER JÚNIOR, A.; RASEIRA, M.C.B.; PIEROBOM, C.R.; FORTES, J.F.; SILVA, J.B. Non-Correlation of Flower and Fruit Resistance to Brown Rot [Monilinia fructicola (Wint.) Honey] Among 27 Peach Cultivars and Selections. Journal of the American Pomological Society, v.59, n.3, p. 148-152, 2005.

WAGNER JÚNIOR, A.; RASEIRA, M.C.B.; PIEROBOM, C.R.; SILVA, J.B.; FRANZON, R.C. Avaliação de diferentes genótipos de pessegueiro quanto à reação a Moniliniafructicola(Wint.) Honey em frutos. Revista Ceres, v. 55, n.2, p.083-088, 2008. 
WAGNER JÚNIOR, A., FABIANE, K.C., OLIVEIRA, J.S.M.A., ZANELA, J., CITADIN, I. Divergência genética em pessegueiros quanto à reação à podridão-parda em frutos. Revista Brasileira de Fruticultura, v.33, n.spe1, p.552-557, 2011. 